\title{
Nawawi al-Bantani, Ashhab al-Jawiyyin di Bidang Hadis: Rihlah, Genealogi Intelektual, dan Tradisi Sanad Hadis
}

\author{
Hafidhuddin \\ Universitas Islam Negeri Sunan Kalijaga Yogyakarta \\ abtohafidh90@gmail.com \\ Saifuddin Zuhri Qudsy \\ Universitas Islam Negeri Sunan Kalijaga Yogyakarta \\ saifuddin.zuhri@uin-suka.ac.id
}

\begin{abstract}
Nawawi al-Bantani as an archipelago scholar through the Tanqih al-Qaul has contributed to the study of hadith in the mid-nineteenth century AD. The intellectual tradition developed by Nawawi al-Bantani became the scientific traditions that developed in Haramayn (Mecca and Medina), and the traditions Islam in the archipelago, especially in Islamic boarding school on an ongoing basis. This study aims to determine the socio-historical intellectual traditions of Nawawi and figh al-hadith contained in the Tanqih al-Qaul. Departing from that, the historical research method is used in uncovering the object of research. The results of this study indicate that the Lubab al-Hadith by al-Suyuthi (d. 911) was first recited by Nawawi al-Bantani in the mid- nineteenth century AD, through the syarah compiled by Nawawi there were seven ideas in the context of understanding hadith (fiqh al-hadith), this refuses the notion that the study of the eyes has not been touched, Nawawi al-Bantani has made efforts in this regard. In addition, Nawawi as sayyid ulama' al-hijaz and musnid, not only compiled hadith books and spread his thoughts in the field of hadith, which at that time was more oriented towards the dialectics of sufism and fiqih. Through Nawawi, the intellectual genealogy traditions called sanad continues to be continuous, especially for students and scholars in the archipelago after that, and brings its own style to the tradition of learning hadith in Indonesia.
\end{abstract}

Keywords: nawawi; genealogy; intellectual; hadith; tanqih al-qaul

\begin{abstract}
Abstrak
Nawawi al-Bantani sebagai ulama Nusantara melalui kitab Tanqih al-Qaul telah berkontribusi dalam studi hadis pada pertengahan abad ke-19 M. Tradisi intelektual yang dikembangkan Nawawi al-Bantani menjadi penghubung antara tradisi keilmuan yang berkembang di Haramayn (Mekah dan Madinah) dan tradisi Islam yang berada di Nusantara terutama di pesantren-pesantren secara kesinambungan. Penelitian ini bertujuan untuk mengetahui tradisi sosio-historis intelektual dari Nawawi al-Bantani dan fiqh al-hadits yang terdapat dalam kitab Tanqih al-Qaul. Berangkat dari hal itu, maka metode historical research digunakan dalam mengungkap objek penelitian. Hasil penelitian ini menunjukkan bahwa kitab Lubab al-Hadits karya al-Suyuthi (w. 911 H.) pertama kali disyarah oleh Nawawi al-Bantani pada pertengahan abad ke-19 M, melalui syarah yang disusun Nawawi terdapat tujuh gagasan dalam konteks pemahaman hadis (fiqh al-hadits), hal ini menepis anggapan bahwa kajian matan belum begitu tersentuh, Nawawi al-Bantani telah melakukan upaya dalam hal tersebut. Selain itu, Nawawi sebagai sayyid ulama' al-hijaz dan musnid, tidak hanya menyusun kitab hadis dan menyebarkan pemikirannya dalam bidang hadis saja, tetapi juga melestarikan periwayatan hadis, yang pada masanya itu lebih banyak berorientasi pada dialetika tasawuf dan fiqih. Melalui Nawawi al-Bantani pula tradisi geneaologi intelektual yang disebut dengan sanad terus menerus berkesibambungan, khususnya bagi kalangan para pelajar, ulama di Nusantara setelahnya, dan membawa corak tersendiri bagi tradisi pembelajaran hadis di Indonesia.
\end{abstract}

Kata Kunci: nawawi; genealogi; intelektual; hadis; tanqih al-qaul 


\section{A. Pendahuluan}

Kiprah Muhammad Nawawi bin 'Umar al-Jawi al-Bantani (selanjutnya ditulis Nawawi) di Haramayn (Mekah dan Madinah) membuat dirinya diakui oleh para sarjana dan ulama belahan dunia Islam. Ia memiliki kontribusi ilmiah yang besar dalam berbagai bidang disiplin ilmu yang ditunjukkan melalui banyak karya-karyanya berupa syarh dalam bidang tafsir, hadis, fiqih, morfologi Arab, tarikh, dan tasawuf. Karyanya Nawawi dalam bidang literatur hadis menjadi fokus peneliti. Kajian-kajian sebelumnya cenderung menyorot metodologi syarah yang mengarah kepada metode tahlili seperti dilakukan Tajuddin ${ }^{1}$ dan Sakinah ${ }^{2}$ terhadap kitab Tanqih al-Qaul. Objek kajian keduanya searah dengan studi komparatif yang dibahas Mohd. Zarif dengan membandingkan karya Nawawi dengan karya Wan Ali yang mengandung kemiripan redaksi, meskipun berbeda dalam segi pemakaian bahasa. ${ }^{3}$ Kholilah dan Bidari mengkaji dua karya Nawawi, Tanqih al-Qaul dan Nashaih al-'Ibad, termasuk Nadhiran ${ }^{4}$ yang membahas Maraqi al-'Ubudiyah, aspek syarah hadis yang dipakai Nawawi menjadi kajian ketiganya. Ia menyatakan bahwa memahami hadis secara tekstual masih dapat dipakai jika indikasiindikasinya sesuai dengan pemahaman yang tepat.

Sementara Burhanuddin, Syamsuddin, dan Saifuddin melakukan pemetaan secara periodik terhadap sejumlah karya dari Nawawi serta studi yang berkaitan dengannya dari tahun 2007-2017, sepanjang tahun itu studi mengenai karya-karya sang tokoh masih sangat minim dilakukan kajian. ${ }^{5}$ Kajian dalam bentuk hagiografis terdapat dalam karya Ghazali, ${ }^{6}$ dan Amirul. ${ }^{7}$ Keduanya lebih banyak menyentuh aspek historis kehidupan, karya-karya mengenai sang tokoh hanya diulas singkat. Berbeda dengan Mas'ud ${ }^{8}$ dan Jajang ${ }^{9}$ lebih membahas intellectual-genealogy Nawawi ketika berada di Mekah dan aspek keterikatan Nawawi dengan ulama-ulama di masanya dan di masa sebelumnya. Penisbatan al-Jawi al-Bantani yang bersanding pada nama Nawawi, secara tidak langsung mengangkat posisi demografis serta ashhab al-jawiyyin sejajar dengan lainnya.

Berpijak pada kajian di atas, bahwa pada aspek pembentukan tradisi intelektual Nawawi terlebih aspek history of ideas yang mengitari lahirnya karya literatur hadis belum tersentuh. Maka dari itu, untuk mengetahui tradisi sosio-historis intelektual sang tokoh, bahwa dalam studi historis ${ }^{10}$ memiliki

${ }^{1}$ Fakhri Tajuddin Mahdy, "Metodologi Syarah Hadis Nabi saw (Telaah Kitab Tanqih al-Qaul al-Hasis fi Syarh Lubab al-Hadis karya Imam Nawawi al-Bantani)" (UIN Alauddin Makassar, 2016).

${ }^{2}$ Fatihatus Sakinah, "Epistemologi Syarah Hadis Nusantara: Studi Syarah Hadith Tanqih al-Qaul al-Hasis fi Syarh Lubab al-Hadis karya Nawawi al-Bantani," Riwayah: Jurnal Studi Hadis, 6. No. 1 (2020) <https://doi.org/10.21043/riwayah.v6i1.6776>.

${ }^{3}$ Muhammad Mustaqim Mohd. Zarif, "Penulisan Karya Hadis Nusantara Abad ke-19: antara Syeikh Nawawi Banten dan Syeikh Wan Ali Kutan al-Kalantani," in Sunnah Nabi Realiti dan Cabaran Semasa, ed. oleh Fauzi Deraman, Ishak Suliaman, dan Faizal Ahmad Shah (Kuala Lumpur: APIUM, 2011), hal. 373-90.

${ }^{4}$ Hedhri Nadhiran, “Kajian Kritis Kitab Maraqi al-'Ubudiyah (Analisis Metode Syarah Hadis Syekh Nawawi al-Bantani)," Jurnal Ilmu Agama, 21.No. 1 (2020).

${ }^{5}$ Mamat S Burhanuddin, Muh. Syamsuddin, dan Saifuddin Zuhri Qudsy, "Kajian Kontemporer terhadap Karya Nawawi Al-Bantani," DINIKA : Academic Journal of Islamic Studies, 4.No. 1 Januari-April (2019) <https://doi.org/10.22515/dinika.v4i1.2061>.

${ }^{6}$ Ahmad Ghazali Muhammad Fathullah, Tuhfah al-Rawi fi Tarjamah al-Syeikh Muhammad Nawawi alJawi (t.tp.).

${ }^{7}$ Amirul Ulum, Syaikh Nawawi al-Bantani, Penghulu Ulama di Negeri Hijaz (Yogyakarta: Global Press, 2019); Amirul Ulum, al-Jawi al-Makki, Kiprah Ulama Nusantara di Haramain (Yogyakarta: Global Press, 2010), hal. 39-63.

${ }^{8}$ Abdurrahman Mas'ud, Intelektual Pesantren Perhelatan Agama dan Tradisi (Yogyakarta: Lkis, 2004), hal. 95-133.

'Jajang A Rohmana, “Authorship of The Jawi 'Ulama' in Egypt, A Contribution of Nawawi Banten and Haji Hasan Mustafa to Sharh Tradition,” Epistemé: Jurnal Pengembangan Ilmu Keislaman, 15.No. 2 Desember (2020) <https://doi.org/10.21274/epis.2020.15.02.221-264>.

${ }^{10}$ Ali Imran Saifuddin Zuhri Qudsy, Model-model Penelitian Hadis Kontemporer (Yogyakarta: Pustaka Pelajar, 2013), hal. 89. 


\section{Hafidhuddin dan Saifuddin Zuhri Qudsy: Nawawi al-Bantani, Ashhab al-Jawiyyin di}

Bidang Hadis: Rihlah, Genealogi Intelektual, dan Tradisi Sanad Hadis

episteme masing-masing yang khas. Setidaknya dapat melengkapi keterbatasan literatur sebelumnya. Berangkat dari hal tersebut, ada tiga pokok permasalahan: (1) bagaimana gagasan Nawawi dalam penulisan literatur hadis?; (2) apa faktor yang mendorong literatur hadis tersebut lahir?; dan (3) bagaimana literatur tersebut mempengaruhi pemikiran hadis di Indonesia?.

Pendekatan sosio-historis intelektual akan digunakan dalam tulisan ini. Secara definitif, Nor Huda mengartikan sebagai tradisi keilmuan, hubungan antara guru dan murid, sejarah pendidikan, dan wacana intelektual yang berkembang. ${ }^{11}$ Perlu dipahami bahwa keberadaan dan karakter seorang tokoh intelektual sangat dipengaruhi oleh situasi dan kondisi yang mengitari dirinya. Selanjutnya tahapantahapan yang dipakai adalah metode historical research. ${ }^{12}$ Seluruh tahapan pelaksanaan penelitian kajian ini bersifat komplementer, yakni saling mengisi dan melengkapi. Tahap pertama melakukan penelitian kepustakaan, dengan cara melacak kitab hadis Tanqih al-Qaul. Guna menunjang sumber data, penulis juga melakukan tinjauan pustaka, berupa artikel ilmiah, ijazah ilmiah (sanad) dan buku. Bahan referensi itu sebagai acuan dalam tahap analisis dan interpretasi. Tahap kedua pengelolaan data, data dianalisis dimaksudkan dilakukan proses pengorganisasian dan penyajian data. Semua hasil pengumpulan data dianalisis secara deskriptif-komparatif. Jika data berseberangan akan dilakukan pemeriksaan ulang. Tahap ketiga atau langkah akhir adalah interpretasi data. Semua data yang diperoleh dapat terintegrasi dari fakta-fakta sejarah melalui kritik sumber, hal demikian agar interpretasi sesuai dengan tujuan penelitian.

Sebagai tokoh multidisipliner, berbagai gelar pujian diperoleh Nawawi di antaranya sayyid ulama' al-hijaz, ${ }^{13}$ al-imam al-muhaqqiq wa al-fahhamah al-mudaqqiq, ${ }^{14}$ imam ulama' al-haramayn, alnawawi al-tsani, ${ }^{15}$ bapak kitab kuning Indonesia, dan doktor ketuhanan. ${ }^{16}$ Pada dasarnya Nawawi dapat dikategorikan sebagai seorang musnid (ahli sanad) era abad pertengahan ke-19 M., dari Nusantara yang berkiprah di Haramayn. Mengingat tradisi intelektual di masa itu, mulai termarjinalkan dengan keadaan politik yang berkembang baik di Timur Tengah maupun di Indonesia. Dalam menjaga tradisi itu agar tidak hilang, peran Nawawi dalam melestarikan tradisi periwayatan hadis, maupun periwayatan kitabkitab terjaga hingga berlangsung di masa setelahnya.

\section{B. Pergumulan Intelektual Nawawi: Hagiografi, Literatur Hadis dan Genealogi}

\section{B.1. Hagiografi}

Tradisi keagamaan yang teguh sejak kecil telah dirasa, hingga membentuk karakter yang tertanam pada kepribadian Abu 'Abd al-Mu'thi Muhammad Nawawi bin 'Umar bin 'Arabi, kelak menjadi ulama berpengaruh di dunia Islam. Ayahnya seorang penghulu di Banten yang diangkat oleh pemerintah Belanda, ${ }^{17}$ 'Umar, dan ibunya bernama Zubaedah. Nawawi lahir di Tanara (sebuah desa

${ }^{11}$ Nor Huda, Sejarah Sosial Intelektual Islam di Indonesia (Jakarta: Rajawali Press, 2015), hal. xi, xvii; Akh. Minhaji, Sejarah Sosial dalam Studi Islam: Teori, Metodologi, dan Implementasi (Yogyakarta: Suka Press, 2013), hal. 46.

${ }^{12}$ Dudung Abdurrahman, Metodologi Penelitian Sejarah Islam (Yogyakarta: Ombak, 2011), hal. 104.

${ }^{13}$ Muhammad Nawawi Al-Jawi, Kasyifah al-Saja Syarh 'ala Safinah al-Najah, ed. oleh Alwi Abu Bakar Muhammad Assegaf (Jakarta: Dar al-Kutub al-Islamiyah, 2008), hal. 8.

${ }^{14}$ Muhammad Nawawi Al-Jawi, Syarh Tijan al-Darari 'ala Risalah al-Bajuri (Surabaya: Dar al-'Ilmi), hal. sampul.

${ }^{15}$ Gelar dari Wan Ahmad bin Muhammad Zayn al-Fathani. LPSI-FK Sejarah, Guru Orang-orang Pesantren (Pasuruan: Pustaka Sidogiri, 2013), hal. 399.

${ }^{16}$ Gelar dari Snouck Hourgronje. Muslimah, "Sejarah Masuknya Islam dan Pendidikan Islam Masa Kerajaan Banten Periode Pra Kemerdekaan,” Jurnal Studi Agama dan Masyarakat, 13.No. 1 Juni (2017), hal. $143<$ https://doi.org/10.23971/jsam.v13i1.576>.

${ }^{17}$ Jajat Burhanudin, Ulama dan Kekuasaan, Pergumulan Elite Muslim dalam Sejarah Indonesia (Jakarta: Mizan, 2012), hal. 114. 
kecil di Kecamatan Tirtayasa, Banten, Jawa Barat) tahun 1230 H./1813 M. ${ }^{18}$ Dari jalur ayah maupun ibunya, secara genealogis ia seorang ulama dzurriyah dari Kesultanan Banten dan Cirebon. ${ }^{19}$ Situasi sosio-politik ketika itu ditandai dengan pemaksaan Gubernur Rafless kepada sultan yang baru saja naik tahta pada 1813 M.,-Sultan Rafi'uddin (sultan Banten terakhir)- untuk menyerahkan estafet kepemimpinan kepada pihak kolonial Belanda, dengan dalih sultan tidak dapat mengatasi keamanan negara. Seiring berjalannya waktu, tiga tahun masa kepemimpinan (1816 M.), terjadi perjanjian antara sultan dengan pemerintah kolonial Belanda, dan inilah akhir dari kesultanan Banten. Istana Banten tahun 1832 M., berpindah ke Serang sistem pun berubah berbentuk struktur pemerintahan, bupati pertama diangkat oleh pihak Belanda adalah Aria Adisenta yang mengantikan Sultan Rafi'uddin. ${ }^{20}$ Satu tahun berjalan, terbentuklah jabatan Residen yang dijabat oleh orang Belanda. Situasi dan kondisi itu yang membuat Nawawi sangat anti kolonialisme.

Orang tua Nawawi selain taat beragama, keduanya sangat perhatian terhadap ilmu terutama dalam bidang keagamaan. Melalui ayahnya, Nawawi belajar al-Qur'an, tafsir, fiqih, nahwu dan ilmu kalam. Tidak hanya belajar kepada ayahnya, ia juga belajar kepada seorang 'alim Banten, Haji Sahal. Bersama saudaranya kemudian pindah belajar kepada Raden Haji Yusuf (w. 1854 M.) di Karawang. Ditegaskan oleh Snouck Hurgronje (1857-1885 M.) bahwa pada usia kecil Nawawi telah hafal alQur'an. ${ }^{21}$ Ketika usia 15 tahun ia melakukan ibadah haji bersama saudaranya, Tamim dan Ahmad, tahun 1828 M. ${ }^{22}$ Peristiwa di mana Raja Ahmad (1778-1878 M.) anak Raja Haji Fisabilillah (raja Riau-Lingga pertama) juga beribadah haji. Tanggal 5 Maret/18 Sya'ban 1243 H., Raja Ahmad tiba di Jeddah dan bergabung dengan sekelompok kafilah sebesar 2.000 unta lebih. Ketika di Madinah Raja Ahmad mewakafkan sebuah kebun untuk dzurriyah Syekh Samman, dan ketika di Mekah ia mewakafkan dua rumah dengan mufti Syafi'i sebagai nazirnya. Hal tersebut menunjukkan bahwa tarekat Sammaniyah mempunyai kedudukan istimewa di tingkat istana, tidak hanya Riau, tetapi Palembang (1777) dan Brunei (1807). Situasi sosio-politik di Mekah (1828) ketika itu mengancam jaringan internasional di seputar ibadah haji, dikarenakan Raja Mekah (Syarif Yahya bin Surur) telah membunuh Syarif Syanbar al-Mun'imi, ${ }^{23}$ tidak lain salah seorang keluarganya sendiri di dalam Masjid al-Haram, berakibat adanya protes dari Raja Istanbul, Sultan Mahmud Khan ketika itu, sehingga orang takut perang akan meletus. Syarif Yahya mendapat informasi bahwa anak raja Jawi pihak negeri Riau, sahabat ayahnya, hendak berhaji maka keselamatan Raja Ahmad dijamin oleh Raja Mekah. ${ }^{24}$

Perkembangan sosio-politik di Banten dan Mekah tidak menyurutkan niat Nawawi beribadah haji. Kedua saudaranya selepas haji berpulang, Nawawi tidak, ia memanfaatkan peluang itu untuk belajar -hingga berlangsung tiga tahun- kepada Ahmad bin 'Abd al-Rahman al-Nahrawi, Ahmad alDimyathi, Ahmad Zayni Dahlan, dan Ahmad Khathib Sambas di Mekah. Dari Madinah ia juga melakukan perjalanan ke Syiria dan Mesir di sana ia belajar kepada Yusuf Sunbulawayni dan 'Abd alHamid al-Daghastani. ${ }^{25}$ Pada 1833 M., ia kembali ke Banten, kedatangannya disambut antusias, sejumlah pelajar meluangkan waktu untuk belajar kepadanya. Pada saat itulah Nawawi melakukan

${ }^{18}$ Muhammad Nawawi Al-Jawi, Nashaih al-'Ibad 'ala al-Munabbihat 'ala al-Isti'dad li Yaum al-Ma'ad, ed. oleh Alwi Abu Bakar Muhammad Assegaf (Jakarta: Dar al-Kutub al-Islamiyah, 2010), hal. 6.

${ }^{19}$ Ulum, Syaikh Nawawi al-Bantani, Penghulu Ulama di Negeri Hijaz, hal. 48.

${ }^{20}$ Kholilah Bidari Siti Nur Kholilah, "Melacak Pemikiran Hadis Syeikh Nawawi al-Bantani," in Menelusuri Jejak Nabi saw, ed. oleh Komnas-Sunnah (Tangerang: alkitabah, 2013), hal. 194.

${ }^{21}$ Mas'ud, hal. 96 (footnote 7).

${ }^{22}$ Siti Nur Kholilah, hal. 195.

${ }^{23}$ Badri Yatim, Sejarah Sosial Keagamaan Tanah Suci (Jakarta: Logos, 1999), hal. 306.

${ }^{24}$ Henri Chambert-Loir, Naik Haji di Masa Silam, Kisah-kisah Orang Indonesia Naik Haji 1482-1964 (Jakarta: KPU, 2019), hal. 236, 239.

${ }^{25}$ Mas'ud, hal. 97 (footnote 10); Karel A. Steenbrink, Beberapa Aspek tentang Islam di Indonesia Abad ke-19 (Jakarta: Bulan Bintang, 1984), hal. 118. 
pengajaran di rumah-rumah, masjid-masjid, dan di pesantren yang didirikan ayahnya. C. Brockelmann dikutip Mas'ud sekitar 1855 M., Nawawi kemudian memutuskan kembali ke Mekah dan menetap di sana. Setidaknya ada tiga alasan: pertama, beribadah haji (pilgrimage); kedua, semangat memperdalam ilmu; dan ketiga, situasi dan kondisi tanah air yang tidak kondusif bagi perkembangan keilmuan dan keagamaan. ${ }^{26}$ Pada 25 Syawal 1314 H./29 Maret 1897 M., Nawawi wafat di Mekah serta dimakamkan di Ma'la. Cucu Nawawi, 'Abd al-Haq (1868-1906 M.) mencatat kepergian kakeknya dalam Tadrij alDani (ditulis 1901 M.). ${ }^{27}$

\section{B.2. Literatur Hadis}

Mengenai karya Nawawi sendiri seperti ditulis muridnya, 'Abd al-Sattar al-Dihlawi (1286-1355 H.) bahwa gurunya telah menyusun $80 \mathrm{kitab}$, antaranya tafsir dalam empat jilid besar, dan dua syarah maulid al-Barzanji, sebagian kitab-kitabnya telah dibaca al-Dihlawi dihadapan gurunya itu yang telah berusia 80 tahun. Nawawi mengijazahkan seluruh kitab-kitabnya kepada al-Dihlawi. ${ }^{28}$ Informasi alDihlawi tersebut terjadi tahun 1893 M., atau empat tahun sebelum Nawawi wafat (1897 M.). ${ }^{29}$ Dalam karya al-Dihlawi lain, ia mencatat bahwa gurunya telah menyusun 100 kitab. ${ }^{30}$ Sedangkan Isma'il Pasha al-Baghdadi (w. 1920 M.) mencatat Nawawi sebagai faqih dan menyusun 315 kitab, serta mencatat Tijan sebagai kitab hadis, ${ }^{31}$ pada dasarnya itu adalah kitab tauhid. Sejumlah karya itu, Mas'ud membagi pada sembilan bidang disiplin ilmu seperti tafsir, fiqih, ushul al-din, teologi, tasawuf, tarikh, morfologi Arab, hadis dan akhlak, kesemua kitab ditulis dalam bahasa Arab dan sebagian besar dalam bentuk syarah. Bruinessen berhasil mengoleksi 27 judul. ${ }^{32}$ Sementara Siradjuddin Abbas hanya mengoleksi lima judul dari 34 kitab yang dicatatnya. ${ }^{33}$ Pertama kali kitab-kitab Nawawi dicetak di Timur Tengah, antaranya di Mekah dan Mesir, hampir kesemua kitabnya dipelajari di dunia Islam, tidak hanya di daerah Jawa saja, setidaknya ada 42 pesantren di seluruh Indonesia, ${ }^{34}$ bisa jadi jumlah ini lebih era sekarang.

Penulis akan mengkaji bidang karya hadis saja. Sebagaimana disinyalir berbagai data, hanya satu karya Nawawi bidang hadis, yaitu Tanqih al-Qaul al-Hatsits sebagai syarah atas Lubab al-Hadits, diduga sebagai karya Jalal al-Din al-Suyuthi. Sebagian peneliti beranggapan Tanqih al-Qaul satusatunya kitab hadis yang disusunnya, tidak sedikit ada yang memasukan Nashaih al-'Ibad syarah dari al-Munabbihat 'ala al-Isti'dad li Yaum al-Ma'ad karya Ibnu Hajar al-'Asqalani, serta Qami' alThughyan (ditulis 1296 H.) syarah dari Manzhumah Syu'ab al-Iman karya Zayn al-Din 'Ali al-Malibari bagian dari kitab hadis, meski didapati kedua kitab itu terkadang dikelompokan sebagai kitab bidang akhlak dan tasawuf, sama seperti Tijan, sebagaimana telah disinggung pada pendahuluan. Melalui

${ }^{26}$ Intelektual Pesantren, Potret Tokoh dan Cakrawala Pemikiran di Era Perkembangan Pesantren 2, ed. oleh M. Ishom El-Saha Mastuki HS (Jakarta: Diva Pustaka, 2004), hal. 115-16.

${ }^{27}$ 'Abd Al-Haq, Tadrij al-Adani ila Qira'ah Syarh al-Sa'd 'ala Tashrif al-Zanjani (t.tp.: Dar al-Ihya' alKutub al-'Arabiyyah), hal. 2, 219.

${ }^{28}$ ' Abd al-Sattar Al-Hindi, Natsr al-Ma'atsir fiman Adraktu min al-Akabir (Manuskrip) (KSA: Maktabah al-Ustadz al-Duktur Muhammad bin Turki), hal. 2 (no. 15), 21.

${ }^{29}$ Rohmana, hal. 235.

30'Abd al-Sattar Al-Hindi, Faydh al-Malik al-Wahhab al-Muta'ali bi Anba' Awail al-Qarn al-Tsalits Asyar wa al-Tawali, ed. oleh 'Abd al-Malik bin 'Abd Allah bin Dahaysy (Mekah: Maktabah al-Asadi), hal. 1637 (no. 1374).

${ }^{31}$ Isma'il Pasha Al-Baghdadi, Hidayah al- 'Arifin Asma' al-Muallifin wa Atsar al-Mushannifin 2 (Istanbul: Muassasah al-Tarikh al-'Arabi, 1951), hal. 394.

${ }^{32}$ Mas'ud, hal. 111; Martin van Bruinessen, Kitab Kuning, Pesantren dan Tarekat (Yogyakarta: Gading Publishing, 2015), hal. 107, 161; Steenbrink, hal. 120.

${ }^{33}$ Koleksi itu tercatat pada 1394 H. Siradjuddin Abbas, Thabaqat al-Syafi 'iyyah: Ulama Syafi'i dan Kitabkitabnya dari Abad ke Abad (Jakarta: Pustaka Tarbiyah, 1975), hal. 447, 450.

${ }^{34}$ Faisal Ahmad Shah Arwansyah, "Peran Syaikh Nawawi Al-Bantani dalam Penyebaran Islam di Nusantara," Kontekstualita: Jurnal Penelitian Sosial Keagamaan, 30.No. 1 (2015), hal. 74; Steenbrink, hal. 120. 
Tanqih al-Qaul sepertinya Nawawi adalah ulama pertama yang memberi syarah atas Lubab al-Hadits terdiri 40 bab, berbicara tentang fadhail al-a'mal, diterangai banyak naskah beredar di masanya mengandung tahrif, distorsi serta belum pernah ditahqiq dan disyarah. Selain itu, banyak di kalangan penduduk Jawa yang membicarakan isi kitab tersebut. ${ }^{35}$ Secara implisit yang dilakukan Nawawi kepada Tanqih al-Qaul telah ada upaya ma'ani al-hadits, lebih mengedepankan aspek teks, namun juga tidak meninggalkan aspek sanad. Tidak ada data mengenai kapan kitab itu diselesaikan.

Pada usia 47 tahun, Nawawi telah menulis dan menerbitkan kitab pertamanya (1276 H./1860 M.) yaitu Fath al-Mujib syarah atas Khathib al-Syarbani fi al-Manasik. ${ }^{36}$ Namun diperkirakan Tanqih al-Qaul ditulis sebelum tahun $1306 \mathrm{H} .{ }^{37}$ dengan merujuk tahun selesai penulisan al-Jauhar al-Mauhub wa Munabbihat al-Qulub karya Wan 'Ali al-Kalantani (1820-1913 M.), ${ }^{38}$ tidak lain terjemahan Arab Melayu dari Lubab al-Hadits. Metode syarah yang dipakai Nawawi ialah metode ijmali (global), yaitu menjelaskan makna hadis dengan singkat, padat dan dapat dimengerti, sistematikanya mengikuti kitab induknya. Selain itu, metode tahlili (analisis) juga digunakan oleh Nawawi, yaitu menganalisis dan menjelaskan makna-makna yang terkandung dalam hadis, aspek-aspek itu dijelaskan sesuai keahlian dari pensyarah, seperti aspek bahasa, kolaborasi riwayat dan qaul ulama. ${ }^{39}$ Dapat dipahami dari kedua metode, Nawawi mengedepankan agar kitab yang disajikan dapat mudah diterima isi dan dipahami maksud pesan yang hendak disampaikan pensyarah dari teks hadis itu. Pada awal kitab, Nawawi terlebih dahulu memberi pengantar tentang 'ulum al-hadits sebagai pengenalan bagi para pembaca agar dapat memahami setiap kedudukan dari status hadis di dalamnya, meski bersifat global.

\section{B.3. Genealogi Intelektual}

Genealogi intelektual dalam konteks adanya networks of the ulama. Kontak intensif dalam tradisi pengetahuan dan keilmuan Islam antara guru dan murid, sebaliknya, memberi kontribusi besar dalam pembentukan karakter istimewa, dan tradisi ilmiah dalam jaringan ulama. Telah disinggung sejumlah guru Nawawi, tetapi informasi lain mencatat nama-nama gurunya di Mekah dari kalangan ulama yang telah lama mukim dan mengajar di Haramayn. Proses intellectual-genealogy ini penting, untuk menjawab guru hadisnya, mengingat ulama dahulu bersifat kosmopolitan. Temuan berharga didapati dari sejumlah tsabat Yasin al-Fadani, ${ }^{40}$ kepada siapa saja Nawawi mencari dan belajar hadis. Sepertinya keberangkatan pertama Nawawi ke Mekah selama tiga tahun, adalah peluangnya mencari ilmu, selain beberapa nama guru dicatat Mas'ud. Al-Fadani mencatat sanad tafsir dan hadis -serta bidang keilmuan lain- yang bersambung kepada Nawawi, antaranya melalui 'Abd al-Shamad bin 'Abd al-Rahman, sesekali ia juga belajar kepada anak dari 'Abd al-Shamad yaitu Fathimah bint 'Abd alShamad, juga Mahmud bin Kenan al-Falimbani, tidak hanya belajar kepada ulama asal Palembang, Nawawi juga talaqqi kitab-kitab hadis dan tafsir kepada gurunya 'Abd al-Shamad, yaitu 'Aqib bin Hasan al-Din al-Falimbani. Selain itu, Nawawi juga belajar kepada ulama asal Banjar, Arsyad bin ‘Abd al-Shamad dan Yusuf bin Arsyad.

\footnotetext{
${ }^{35}$ Muhammad Nawawi Al-Jawi, Tanqih al-Qaul al-Hatsits fi Syarh Lubab al-Hadits (Indonesia: Dar Ihya' al-Kutub al-'Arabiyah), hal. 2.

${ }^{36}$ Mastuki HS, hal. 122; Zarif, hal. 357.

37' Ali bin 'Abd al-Rahman Al-Kalantani, al-Jauhar al-Mauhub wa Munabbihat al-Qulub (Pulau Pinang: Percetakan al-Mu'arif), hal. 229.

${ }^{38}$ Abdul Aziz Muslih, Sketsa Genealogi Kajian Hadis di Indonesia dari Masa Kerajaan hingga Pascakemerdekaan (Jawa Tengah: Sanjemedia Kebumen, 2016), hal. 50.

${ }^{39}$ Mahdy; M. Alfatih Suryadilaga, Metodologi Syarah Hadis (Yogyakarta: Suka Press, 2012), hal. 30, 18 19.

${ }^{40}$ Muhammad Yasin bin 'Isa Al-Fadani, al- 'Iqd al-Farid min Jawahir al-Asanid (t.tp.).
} 


\section{Hafidhuddin dan Saifuddin Zuhri Qudsy: Nawawi al-Bantani, Ashhab al-Jawiyyin di Bidang Hadis: Rihlah, Genealogi Intelektual, dan Tradisi Sanad Hadis}

Setelah menetap di Haramayn, Nawawi banyak berguru, guru lainnya seperti 'Abd al-Ghani Bima dari Sumbawa, ${ }^{41}$ Ahmad al-Murshafi al-Mishri, al-Khatib al-Syami al-Hanbali, ${ }^{42}$ "Ali al-Rahbini, Utsman al-Dimyathi, dan Bisyri al-Jabarti. Azra mencatat 'Abd al-Shamad wafat 1203 H./1789 M.43 Jika sumber ini dipakai artinya tidak ada interaksi antara Nawawi dengan 'Abd al-Shamad, seperti asumsi Bruinessen. ${ }^{44}$ Sumber Palembang mencatat bahwa 'Abd al-Shamad hidup dari 1737-1832 M. ${ }^{45}$ Jelas ada interaksi intensif antar keduanya, begitu juga dengan 'Aqib bin Hasan al-Din (1760-1849 M.). Fathimah bint Abd al-Shamad mengajar Shahih al-Bukhari di Haramayn, Nawawi adalah salah satu muridnya yang populer, yang menjadi guru dari Sholeh Darat al-Samarani dan Mahfuzh al-Tarmasi, juga Asnawi Kudus ketika belajar di Haramayn. ${ }^{46}$ Penelitian Shafiyah bint Idris Fallatah sepanjang abad ke-4 H., sampai 14 H., Fathimah bint 'Abd al-Shamad adalah satu dari tiga ulama ahli hadis perempuan di abad 14 H./19 M., yang melestarikan periwayatan Shahih al-Bukhari dan Shahih Muslim, dua ulama perempuan lainnya adalah Ummah Allah bint 'Abd al-Ghani bin Abu Sa'id Ahmad al-Dihlawi dan Fathimah bint Muhammad Ya'qub al-Makki. ${ }^{47}$ Dari sejumlah gurunya, dapat dilihat kesungguhan Nawawi dalam belajar hadis.

Di antara muridnya berasal dari kepulauan Nusantara adalah Hadji Hasan Mustafa, Ahmad Syuja'i al-Qanturi, Tubagus Ahmad Bakri Purwakarta, Hasyim Asy'ari, Ahmad Dahlan, dan Jamal alDin bin 'Abd al-Khaliq al-Fathani (1861-1936 M.). ${ }^{48}$ Termasuk cucunya sendiri, 'Abd al-Haq bin 'Abd al-Mannan (sibth al-'allamah al-nawawi al-tsani ${ }^{49}$ ) yang digadang sebagai penerus intelektual dari kakeknya, tetapi usianya tidak panjang. Sementara di Haramayn saja, seperti dicatat 'Abd al-Sattar bahwa ada sekitar 200 murid yang senantiasa mengikuti halaqah Nawawi. ${ }^{50}$ Tradisi intelektual yang berakar di kalangan ulama mutaqaddimin dan muta'akhkhirin adalah memelihara genealogi intelektual antara satu dengan lain, antara ulama terdahulu dengan yang kemudian. Maka dipeliharanya hubungan itu, dalam rangka menjaga kesinambungan pemahaman Islam yang telah diwariskan oleh salafal-shalih, dan mengkristal dalam sebuah networks of the ulama, yang dijadikan patron untuk mengukur kredibilitas keulamaan seseorang. Keadaan demikian betapa kecintaan Nawawi kepada ilmu pengetahuan ada sejak kecil hingga membentuk karakter yang tertanam, sederet gelar yang diberikan ulama semasanya dan setelahnya membuktikan penguasaan ilmunya yang mendalam.

\section{Kiprah Nawawi dalam Tradisi Intelektual Hadis}

Kredibilitas Nawawi selaku ulama tidak terlepas dari keterlibatan dalam networks of the ulama. Dari banyaknya guru tersebut, Ahmad al-Nahrawi, Junayd al-Batawi, dan Ahmad al-Dimyathi adalah guru-guru yang berpengaruh bagi Nawawi ketika remaja. Selain itu, dalam bagian kedua rihlah $f i$

${ }^{41}$ Steenbrink, hal. 118.

${ }^{42}$ Al-Jawi, Nashaih al- 'Ibad 'ala al-Munabbihat 'ala al-Isti'dad li Yaum al-Ma'ad, hal. 7-8.

${ }^{43}$ Azyumardi Azra, Jaringan Ulama Timur Tengah dan Kepulauan Nusantara Abad XVII dan XVIII Akar Pembaruan Islam Indonesia, Parenial (Jakarta: Kencana, 2013), hal. 320.

${ }^{44}$ Bruinessen, hal. 390 (footnote 20).

${ }^{45} \mathrm{Mal}$ An Abdullah, Syeikh Abdus-Samad al-Palimbani, Biografi dan Warisan Keilmuan (Jakarta: Gramedia, 2018), hal. 21, 113.

${ }^{46}$ Amirul Ulum, Nyai Khairiyah Hasyim Asy'ari Pendiri Madrasah Kuttabul Banat di Haramayn (Yogyakarta: Global Press, 2019), hal. 184.

${ }^{47}$ Shafiyah bint Idris Al-Fallatah, Daur al-Nisa' fi al-'Inayah bi al-Shahihayn -riwayah- min Qarn alRabi' al-Hijri hatta al-Qarn al-Rabi' 'Asyar al-Hijri (Universitas Jordan, 2010), hal. 420.

${ }^{48}$ A. Ginanjar Sya'ban, Mahakarya Islam Nusantara, Kitab, Naskah, Manuskrip dan Korespondensi Ulama Nusantara (Ciputat: Pustaka Compass, 2017), hal. 211; Dzulkifli Amnan, Jalan Dakwah Ulama Nusantara di Haramayn Abad 17-20 M (Ciputat: Pustaka Compass, 2018), hal. 63.

${ }^{49} \mathrm{Al}-\mathrm{Haq}$, hal. sampul. Cucunya, 'Abd al-Haq menulis dua kitab dalam bidang sintaksis Arab (sharf) dan ushul al-fiqh.

${ }^{50}$ Al-Hindi, Faydh al-Malik al-Wahhab al-Muta'ali bi Anba' Awail al-Qarn al-Tsalits Asyar wa alTawali, hal. 1637; Rohmana, hal. 235. 
thalab al-'ilmi terdapat dua nama yang juga sangat mempengaruhi kepribadian Nawawi, yaitu Ahmad Zayni Dahlan dan al-Khatib al-Hanbali. Pengaruh itu tidak hanya berdampak pada karekter Nawawi, tetapi mempengaruhi dari sejumlah karya yang ditulisnya, seperti dalam Nur al-Zhalam (bidang teologi), Nawawi sering mengutip perkataan gurunya dari Mesir, Ibrahim al-Bajuri (1783-1860 M.), ${ }^{51}$ juga terpengaruh dengan Utsman al-Dimyathi, murid dari al-Amir al-Kabir sekaligus guru dari Ahmad Zayni Dahlan. ${ }^{52}$ Disinggung sebelumnya, setidaknya ada lima guru yang memberi pengaruh Nawawi dalam bidang hadis, 'Abd al-Shamad al-Falimbani kepadanya Nawawi banyak menghadiri halaqah dan mengambil sanad, di antaranya al-Muwaththa' Malik dan Musnad al-Syafi'i. Kepada 'Aqib gurunya 'Abd al-Shamad, Nawawi mengambil sanad al-Adzkar dan Riyadh al-Shalihin. Nawawi juga banyak hadir pada halaqah Mahmud bin Kenan dan Arsyad al-Banjari, melalui keduanya Nawawi mendapat sanad Shahih Muslim dan bidang lain. Sedangkan sanad Shahih al-Bukhari didapat Nawawi melalui jalur anak perempuan (bergelar syaikhah) dari 'Abd al-Shamad al-Falimbani sendiri, yaitu Fathimah.

Apabila merujuk Tanqih al-Qaul, dapat dikemukakan gagasan-gagasan Nawawi dalam konteks pemahaman (figh) hadis: pertama, pentingnya mengetahui istilah-istilah yang dipakai dalam kitab-kitab hadis (mushthalah al-hadits), seperti isnad, matn, shahih, dha 'if, dan lainnya; kedua, penting memahami kelemahan (dha'if) suatu hadis, terlebih dalam fadhail al-a'mal; ketiga, menjaga kehati-hatian dalam menilai kedudukan suatu hadis; keempat, menghindari pemahaman yang berbelit-belit; kelima, penting mengetahui gharib al-hadits; keenam, sedapat mungkin mengeluarkan hadis dari kitab induk (takhrij al-hadits); dan ketujuh, pentingnya mengkonfirmasi teks hadis dengan al-Qur'an, hadis setema, dan juga merujuk pendapat para ulama terdahulu. Ketujuh gagasan tersebut, yang menjadi konsep fiqh al-hadits dari Nawawi, penulis temukan secara global dari Tanqih al-Qaul. Nawawi terkesan lebih berorientasi pada matan, kurang memberi perhatian cukup mendalam tentang sanad. Namun demikian, tidak berarti Nawawi memandang keberadaan sanad hadis tidak penting. Secara tegas Nawawi tetap mengakui pentingnya nilai sanad dalam suatu hadis, seperti disinggung pada pengantar kitabnya.

Secara konten, Nawawi dalam Tanqih al-Qaul banyak mengutip dari Ihya' al-Ghazali dalam memberikan uraian atas beberapa hadis yang dibahasnya, tentu keadaan ini memberi kesan bahwa syarih menekankan kepada ajaran tasawuf, meskipun tidak setiap hadis dikemukakan pendapat al-Ghazali. Pengaruh al-Ghazali dalam dunia Islam, terutama dalam pemikiran syarih salah satunya, karena alGhazali dapat mengubah istilah-istilah yang pelik menjadi lebih mudah dicerna oleh akal orang awam. ${ }^{53}$ Boleh jadi hal yang dilakukan syarih agar uraian hadis dapat mudah dipahami oleh masyarakat secara luas, dari berbagai kalangan, sebagaimana dalam pendahuluan kitabnya, mengenai latar belakang syarah tersebut disusun.

Sebagai ulama yang juga pernah mengajar di Masjid al-Haram, ${ }^{54}$ melalui Nawawi banyak di antara pelajar beragam daerah mewarisi tradisi intelektual Nawawi, termasuk pada bidang hadis, seperti muridnya, 'Abd al-Sattar ad-Dihlawi dikenal bermazhab Hanafi yang ahli sejarah, dan hadis. Sahabatnya, Muhammad Mahfuzh al-Tarmasi (1868-1919 M.) yang berpengaruh di masanya mengajar Shahih al-Bukhari di Masjid al-Haram, termasuk transmitter dan pemikiran hadis di Indonesia, juga

\footnotetext{
${ }^{51}$ Adhi Maftuhin, Sanad Ulama Nusantara, Transmisi Keilmuan Ulama Al-Azhar dan Pesantren disertai Biografi Penulis Kitab Kuning (Depok: Sahifa Publishing, 2018), hal. 28, 68.

${ }^{52}$ Genealogi intelektual Nawawi terhubung kepada Ahmad Zayni Dahlan, dapat dieksplor melalui tsabatnya. Ahmad bin Zayni Dahlan Al-Makki, Marwiyat wa Ijazat (Manuskrip) (t.tp., 1329).

${ }^{53}$ Ahmad Zaini, "Pemikiran Tasawuf Imam Al-Ghazali," ESOTERIK, 2.1 (2017), hal. 151 <https://doi.org/10.21043/esoterik.v2i1.1902>.

${ }^{54}$ Moh Abid Mabrur, "Pengaruh Karya Syekh Nawawi al-Bantani dalam Tradisi Kajian Kitab Kuning (Kitab Klasik) di Pesantren Buntet," TAMADDUN, 4.Ed. 2 Juli-Desember (2016), hal. 78; Hilful Fudhul Sirajuddin Jaffar, Jaringan Ulama dan Islamisasi Indonesia Timur, Peta dan Jejak Islam di Nusantara (Yogyakarta: IRCiSoD, 2020), hal. 63.
} 
berguru kepada Nawawi. ${ }^{55}$ Murid lainnya sekaligus sahabat Nawawi adalah Ahmad al-Khathib alMinangkabawi (1859-1915 M.) sebagai pengajar, imam, khatib dan juga sebagai mufti madzhab Syafi'i di Masjid al-Haram. ${ }^{56}$ Jika Ahmad al-Khathib berpusat di Mekah, murid Nawawi yang menjadi pusat di Minangkabau adalah Sa'ad Mungka (1857-1922 M.). ${ }^{57}$ Muhammad Khalil al-Bangkalani, Madura (1820-1925 M.) termasuk guru dari al-Tarmasi, juga murid dari Nawawi yang menjadi penghubung tradisi keilmuan sejumlah pesantren di Indonesia. Sebagian murid-muridnya membawa kesinambungan tradisi keilmuan pesantren tidak hanya bidang hadis, tetapi bidang lain, seperti tafsir, ushul al-fiqh, tasawuf dan gramatika bahasa Arab, tidak jarang beredar karya-karya Nawawi di berbagai pesantren di Indonesia, bahkan dunia Islam, termasuk di antara murid-muridnya juga menulis berbagai disiplin keilmuan, hingga sekarang masih dapat ditemukan.

Sepanjang abad ke-19 M. ${ }^{58}$ perkembangan studi hadis di Nusantara dalam konteks dahulu, tidak begitu menggairahkan, boleh jadi pengkajian dan pengajaran hadis lebih pada aspek periwayatan saja, tetapi dalam tradisi literasi hadis di kalangan pelajar, sarjana, atau ulama masih sangat terbatas, terlebih di Indonesia. Keadaan demikian secara sosio-politik historis, berpengaruh dengan posisi Indonesia dalam kuasa kolonial, terutama awal abad ke-19 M. Sebagaimana Nawawi sering menyuarakan negerinya untuk terbebas dari jeratan jajahan kolonialisme, tindakan itu juga menghambat perkembangan keagamaan Islam di Indonesia. Berkaitan dengan tradisi pesantren, Nawawi memiliki kedudukan istimewa dalam hubungannya dengan perkembangan intelektual dan produksi ulama di dunia Islam. Selama kurang lebih 30 tahun (dari 1830-1860 M.), Nawawi melakukan rihlah fi thalab al-ílmi. Tafsir Marah Labid (1305 H.) sebagai karya masterpiece, membawa dirinya disegani dan digelari sayyid ulama' al-hijaz, terlebih oleh ulama Mesir. 'Abd al-Sattar ${ }^{59}$ memberi penghargaan kepada gurunya, dengan mencatat hagiografinya dengan gelar khatimah al-mufassirin wa al-musnidin.

Ashhab al-jawiyyin, sepanjang abad ke-19 M., di Mekah yang terdiri dari berbagai ulama dari berbagai daerah di Nusantara, aktif dalam rihlah fi thalab al-ilmi dan juga produktif dalam dunia literasi. Kesemuanya saling berinteraksi intensif secara langsung maupun tidak langsung. Bagi para ulama, thalab al-'ilmi di Mekah mempunyai dampak besar bagi keberlangsungan pesantren, dengan cara tersebut mereka membangun otoritas keagamaan di antara umat Islam. Oleh karena itu, rihlah $f i$ thalab al-'ilmi menjadi suatu konsep agama yang utama bagi umat Islam, tema utama adalah penguasaan ilmu-ilmu Islam. Dengan demikian keberadaan ulama di Mekah, seperti Nawawi, 'Abd al-Karim alBantani, al-Tarmasi, al-Khathib al-Minangkabawi dan lain sebagainya memiliki peran strategis. Posisi intelektual terkemuka di Timur Tengah tidak hanya mereka dapat, tetapi juga sebagai transmitter Islam dan kesinambungan sanad ke Nusantara. ${ }^{60}$ Hurgronje didasari informasi asistennya, Raden Aboe Bakar

\footnotetext{
${ }^{55}$ Nawawi dan al-Tarmasi merupakan murid dari Ahmad Khathib Sambas dari Borneo. Ading Kusdiana, Sejarah Pesantren, Jejak, Penyebaran, dan Jaringannya di Wilayah Priangan (1800-1945) (Bandung: Humaniora, 2014), hal. 235 (lihat bagan 4.1.); Muhajirin Gafar, Muhammad Mahfud al-Tarmasi (1868-1919 M) Ulama Hadis Nusantara Pertama (Yogyakarta: Idea Press, 2014), hal. 55.

${ }^{56}$ Azyumardi Azra, Renaisans Islam Asia Tenggara Sejarah Wacana dan Kekuasaan (Bandung: PT Remaja Rosdakarya, 1999), hal. 154; Azra, Jaringan Ulama Timur Tengah dan Kepulauan Nusantara Abad XVII dan XVIII Akar Pembaruan Islam Indonesia, hal. 396.

${ }^{57} \mathrm{Sa}$ 'ad Mungka ke Yaman, Madinah dan Mekah -beribadah haji- juga thalab al- ilmi kepada sejumlah ulama di sana dari tahun 1894-1898 M., dan 1912-1915 M. Apria Putra dan Chairullah Ahmad, Bibliografi Karya Ulama Minangkabau Awal Abad XX, Dinamika Intelektual Kaum Tua dan Kaum Muda (Padang: Komunitas Suluah-IHC, 2011), hal. 37-38; Siradjuddin Abbas, Sejarah dan Keagungan Madzhab Syafi'i (Jakarta: Pustaka Tarbiyah Baru, 2006), hal. 249-50.

${ }^{58}$ Muslih.

${ }^{59}$ Al-Hindi, Faydh al-Malik al-Wahhab al-Muta'ali bi Anba' Awail al-Qarn al-Tsalits Asyar wa alTawali, hal. 1638.

${ }^{60}$ Zainul Milal Bizawie, Masterpiece Islam Nusantara Sanad dan Jejaring Ulama-Santri (1830-1945) (Ciputat: Pustaka Compass, 2016), hal. 418-19.; Amnan, hal. 60.
} 
Djajadiningrat (1854-1914 M.) mencatat bahwa ulama Jawi terlibat dalam pembelajaran Islam sekaligus interaksi sosio-intelektual, pada gilirannya menjadi bagian dari networks of the ulama di antara ashhab al-jawiyyin. Dengan demikian, Mekah pada akhir abad 19 M., menjadi pusat pencetak ulama, seiring dengan keberadaannya sebagai tujuan untuk thalab al-ilmi bagi umat Islam. ${ }^{61}$

Dalam konteks studi hadis, Nawawi turut berkontribusi dalam tradisi literasi hadis pada abad ke-19, sebelumnya abad 17 M., studi hadis dipelopori dengan munculnya karya atas dua ulama, 'Abd al-Ra'uf al-Fansuri (w. 1693 M.) dengan, Syarh al-Lathif 'ala al-Arba'in Hadits lil Imam al-Nawawi dan al-Mawa'izh al-Badi'ah, dan Nur al-Din al-Raniri (w. 1658 M.) dengan, al-Fawaid al-Bahiyyah fi al-Ahadits al-Nabawiyyah. ${ }^{62}$ Upaya yang dilakukan keduanya disinyalir oleh Muslih, lebih fokus pada aspek fiqih dan akhlak, tidak menyentuh aspek sanad dan matan. ${ }^{63}$ Tanqih al-Qaul bukan satu-satunya kitab -dalam bingkai fiqh al-hadits- yang ada (beredar), Wan 'Ali menulis bidang sama dengan cara menerjemahkan Lubab al-Hadits ke bahasa Melayu, dua ulama telah mengisi khazanah hadis di Nusantara di pertengahan abad ke-19, bukan berarti studi hadis tidak berkembang seperti bidang lain. Karya keduanya amat berpengaruh dalam kalangan umat Islam di Nusantara, bahkan karya Nawawi digunakan di beberapa pengajian agama, dan pesantren-pesantren di Indonesia.

Sebagai ulama ensiklopedis, Nawawi selalu merespon setiap persoalan yang datang kepadanya, untuk ditemukan solusinya, seperti respon masyarakat Jawa ketika itu, terkait Lubab al-Hadis. Sebagai syarih, Nawawi menggunakan bahasa Arab, hal sama yang dilakukan pada setiap karyanya, artinya masyarakat Jawa ketika itu merupakan kaum terpelajar yang butuh penjelasan dari hadis-hadis di dalam Lubab al-Hadits. Penting dicatat bahwa kitab-kitab yang disyarah oleh Nawawi memiliki kedudukan penting dalam lanskap intelektual baik di Mekah ataupun Mesir. Di samping, percetakan telah mengambil peran dalam mendistribusikan karya-karya Nawawi di pelosok dunia Islam. Percetakan di Mesir akhir abad 19 M., melakukan litografi atas karya-karya Nawawi, seperti Suluk al-Jaddah (1883), Lubab al-Bayan (1884), Sullam al-Munajat (1884) dan Dzari'ah al-Yaqin (1886). ${ }^{64}$ Keadaan demikian membuktikan bahwa karya-karya Nawawi -dan juga karya-karya ulama lain- berkembang menjadi kitab daras dalam pembelajaran Islam di pesantren.

Apa yang dilakukan Nawawi sebagai syarih, telah melakukan tiga hal, apa yang ditulis Mujiyo sebagai kegunaan syarah itu sendiri: pertama, menyampaikan amanah dan penyebarluasan sunnah Nabi saw; kedua, menghidup-hidupkan serta melestarikan sunnah Nabi saw; dan ketiga, menghindari kesalahpahaman terhadap maksud dari hadis. ${ }^{65}$ Meski ada 404 hadis -dalam Tanqih al-Qaul-pada 40 bab, hanya 360 hadis yang disyarah oleh Nawawi, sisanya 44 hadis tidak disyarah -ditampilkan apa adanya-, boleh jadi hadis-hadis tersebut dianggap telah jelas, sehingga tidak akan menimbulkan kesalahpahaman pembaca. Dalam hal ini, Nawawi sebagai syarih telah mampu menghidupkan isi karyanya, sehingga pembaca dapat paham apa yang hendak disampaikan oleh syarih, selain aspek penggunaan bahasa sangat mempengaruhi suatu tulisan, di samping keluasan ilmu yang luar biasa itu yang kemudian karya-karyanya hingga sekarang masih dibaca dan dikaji oleh pesantren di Indonesia secara khusus, dan secara umum dunia Islam.

Dalam konteks studi hadis di Indonesia, selayaknya apa yang telah dilakukan oleh para ulama terdahulu, seperti Nawawi dan lainnya, dapat dijadikan pemicu bagi sejumlah pengkaji hadis, ataupun pelajar -terutama di pesantren- agar riset terkait tokoh-tokoh hadis yang telah dikenal di dunia Islam

\footnotetext{
${ }^{61}$ Burhanudin, Ulama dan Kekuasaan, Pergumulan Elite Muslim dalam Sejarah Indonesia, hal. 110-11; Jajat Burhanudin, Islam dalam Arus Sejarah Indonesia (Jakarta: Kencana, 2017), hal. 266-67.

${ }^{62}$ Azra, Jaringan Ulama Timur Tengah dan Kepulauan Nusantara Abad XVII dan XVIII Akar Pembaruan

Islam Indonesia, hal. 234-35, 260.

${ }^{63}$ Muslih, hal. 65.

${ }^{64}$ Burhanudin, Islam dalam Arus Sejarah Indonesia, hal. 316.

${ }^{65}$ Mujiyo Nurkholis, Metode Syarah Hadis (Bandung: Fasygil Grup, 2005), hal. 18-21.
} 


\section{Hafidhuddin dan Saifuddin Zuhri Qudsy: Nawawi al-Bantani, Ashhab al-Jawiyyin di}

Bidang Hadis: Rihlah, Genealogi Intelektual, dan Tradisi Sanad Hadis

atau tokoh ulama lokal, terkait karya-karya mereka di bidang hadis tidak hanya dibaca dan dipelajari sebagai kitab daras saja, tetapi bagaimana kitab-kitab terkait hadis ataupun 'ulum al-hadits itu mampu berkomunikasi di era sekarang. Selain produktif dalam dunia literasi hadis, para pengkaji hadis di Indonesia era sekarang harus mampu hadir sebagai kasalitator ${ }^{66}$ dan edukator. ${ }^{67}$ Hal tersebut dilakukan agar hadis tidak hanya hidup dalam kajian saja, akan tetapi secara aplikatif dapat mempengaruhi lingkungan sekitar dengan mengamalkan apa yang telah dikaji dan dipelajari dari teks-teks hadis Nabi saw maupun dari pemikiran dan sosok tokoh-tokoh hadis.

\section{Penutup}

Secara historis, abad ke-19 M. terjadi kekosongan ulama Nusantara yang menulis karya hadis. Karya ulama Nusantara lebih didominasi oleh karya dalam bidang fiqih dan tasawuf. Nawawi sebagai tokoh berpengaruh di Timur Tengah, telah melakukan upaya pengkajian terhadap karya al-Suyuthi yaitu Lubab al-Hadits. Upaya ini mendorong Nawawi mengelola beberapa naskah yang beredar di masa itu untuk kemudian dilakukan pensyarahan, selain respon dari masyarakat Jawa ketika itu. Sebagai seorang musnid, Nawawi telah menghidupkan kembali tradisi intelektual yang sempat termarjinalkan di Timur Tengah, karena dampak dari politik yang berkembang di masa itu. Wujud dari menghidupkan tradisi intelektual itu adalah dengan adanya upaya pelestarian periwayatan sanad hadis dan kitab-kitab, selain itu juga semangat literasi dalam melahirkan karya-karya yang berbobot di berbagai aspek ilmu yang digagas Nawawi.

Gagasan pemikiran Nawawi banyak dikembangkan oleh sejumlah muridnya, baik di Timur Tengah maupun di Indonesia dan tidak sedikit dari mereka belajar dan membaca karya-karya ulama hingga khatam dalam berbagai bidang keilmuan, setelah itu meminta untuk diijazahkan sebagai bukti legalitas dan penjagaan tradisi keislaman. Selain itu, abad pertengahan ke-19 M. dalam konteks Nusantara dapat menepis anggapan sebagian ulama ataupun peneliti bahwa kajian matan belum begitu tersentuh. Adanya karya Nawawi dalam bidang hadis dalam konteks fiqh al-hadits menjadi acuan bahwa kajian matan hadis telah diupayakan oleh Nawawi. Keterkaitan penelitian ini dapat dikembangkan lebih luas dengan penelitian tokoh atau karya hadis lokal yang telah banyak berkontribusi dalam mengisi literatur hadis di Indonesia dan dapat dilihat kesinambungan perkembangannya yang masih jauh dari sentuhan para peneliti, hal tersebut setidaknya mengangkat wacana penting dalam tradisi intelektual keagamaan.

\section{DAFTAR PUSTAKA}

Abbas, Siradjuddin, Sejarah dan Keagungan Madzhab Syafi’i (Jakarta: Pustaka Tarbiyah Baru, 2006)

- Thabaqat al-Syafi'iyyah: Ulama Syafi'i dan Kitab-kitabnya dari Abad ke Abad (Jakarta: Pustaka Tarbiyah, 1975)

Abdullah, Mal An, Syeikh Abdus-Samad al-Palimbani, Biografi dan Warisan Keilmuan (Jakarta: Gramedia, 2018)

Abdurrahman, Dudung, Metodologi Penelitian Sejarah Islam (Yogyakarta: Ombak, 2011)

Al-Baghdadi, Isma'il Pasha, Hidayah al-'Arifin Asma' al-Muallifin wa Atsar al-Mushannifin 2 (Istanbul: Muassasah al-Tarikh al-'Arabi, 1951)

Al-Fadani, Muhammad Yasin bin 'Isa, al-'Iqd al-Farid min Jawahir al-Asanid (t.tp.)

Al-Fallatah, Shafiyah bint Idris, Daur al-Nisa' fi al-'Inayah bi al-Shahihayn -riwayah- min Qarn alRabi' al-Hijri hatta al-Qarn al-Rabi' 'Asyar al-Hijri (Universitas Jordan, 2010)

Al-Haq, 'Abd, Tadrij al-Adani ila Qira'ah Syarh al-Sa'd 'ala Tashrif al-Zanjani (t.tp.: Dar al-Ihya' al-

${ }^{66}$ Melakukan perubahan mendasar dalam kehidupan melalui kajian tematik untuk setiap bidang keilmuan yang berdampak pada kehidupan berbangsa dan bernegara.

${ }^{67}$ Mengkaji hadis Nabi saw secara inklusif, baik yang bersifat subtantif maupun formatif untuk dapat menuntut umat menghidupkan sunnah Nabi saw yang bersifat rahmat yang universal, dalam bidang apa saja. 
Kutub al-'Arabiyyah)

Al-Hindi, 'Abd al-Sattar, Faydh al-Malik al-Wahhab al-Muta'ali bi Anba' Awail al-Qarn al-Tsalits Asyar wa al-Tawali, ed. oleh 'Abd al-Malik bin 'Abd Allah bin Dahaysy (Mekah: Maktabah alAsadi)

—, Natsr al-Ma'atsir fiman Adraktu min al-Akabir (Manuskrip) (KSA: Maktabah al-Ustadz alDuktur Muhammad bin Turki)

Al-Jawi, Muhammad Nawawi, Kasyifah al-Saja Syarh 'ala Safinah al-Najah, ed. oleh Alwi Abu Bakar Muhammad Assegaf (Jakarta: Dar al-Kutub al-Islamiyah, 2008)

—, Nashaih al-'Ibad 'ala al-Munabbihat 'ala al-Isti'dad li Yaum al-Ma'ad, ed. oleh Alwi Abu Bakar Muhammad Assegaf (Jakarta: Dar al-Kutub al-Islamiyah, 2010)

—, Syarh Tijan al-Darari 'ala Risalah al-Bajuri (Surabaya: Dar al-'Ilmi)

—, Tanqih al-Qaul al-Hatsits fi Syarh Lubab al-Hadits (Indonesia: Dar Ihya' al-Kutub al'Arabiyah)

Al-Kalantani, 'Ali bin 'Abd al-Rahman, al-Jauhar al-Mauhub wa Munabbihat al-Qulub (Pulau Pinang: Percetakan al-Mu'arif)

Al-Makki, Ahmad bin Zayni Dahlan, Marwiyat wa Ijazat (Manuskrip) (t.tp., 1329)

Amnan, Dzulkifli, Jalan Dakwah Ulama Nusantara di Haramayn Abad 17-20 M (Ciputat: Pustaka Compass, 2018)

Arwansyah, Faisal Ahmad Shah, "Peran Syaikh Nawawi Al-Bantani dalam Penyebaran Islam di Nusantara," Kontekstualita: Jurnal Penelitian Sosial Keagamaan, 30.No. 1 (2015)

Azra, Azyumardi, Jaringan Ulama Timur Tengah dan Kepulauan Nusantara Abad XVII dan XVIII Akar Pembaruan Islam Indonesia, Parenial (Jakarta: Kencana, 2013)

—, Renaisans Islam Asia Tenggara Sejarah Wacana dan Kekuasaan (Bandung: PT Remaja Rosdakarya, 1999)

Bizawie, Zainul Milal, Masterpiece Islam Nusantara Sanad dan Jejaring Ulama-Santri (1830-1945) (Ciputat: Pustaka Compass, 2016)

Bruinessen, Martin van, Kitab Kuning, Pesantren dan Tarekat (Yogyakarta: Gading Publishing, 2015) Burhanuddin, Mamat S, Muh. Syamsuddin, dan Saifuddin Zuhri Qudsy, "Kajian Kontemporer terhadap Karya Nawawi Al-Bantani," DINIKA : Academic Journal of Islamic Studies, 4.No. 1 JanuariApril (2019) <https://doi.org/10.22515/dinika.v4i1.2061>

Burhanudin, Jajat, Islam dalam Arus Sejarah Indonesia (Jakarta: Kencana, 2017) , Ulama dan Kekuasaan, Pergumulan Elite Muslim dalam Sejarah Indonesia (Jakarta: Mizan, 2012)

Chambert-Loir, Henri, Naik Haji di Masa Silam, Kisah-kisah Orang Indonesia Naik Haji 1482-1964 (Jakarta: KPU, 2019)

Fathullah, Ahmad Ghazali Muhammad, Tuhfah al-Rawi fi Tarjamah al-Syeikh Muhammad Nawawi alJawi (t.tp.)

Gafar, Muhajirin, Muhammad Mahfud al-Tarmasi (1868-1919 M) Ulama Hadis Nusantara Pertama (Yogyakarta: Idea Press, 2014)

Huda, Nor, Sejarah Sosial Intelektual Islam di Indonesia (Jakarta: Rajawali Press, 2015)

Jaffar, Hilful Fudhul Sirajuddin, Jaringan Ulama dan Islamisasi Indonesia Timur, Peta dan Jejak Islam di Nusantara (Yogyakarta: IRCiSoD, 2020)

Kusdiana, Ading, Sejarah Pesantren, Jejak, Penyebaran, dan Jaringannya di Wilayah Priangan (18001945) (Bandung: Humaniora, 2014)

Mabrur, Moh Abid, "Pengaruh Karya Syekh Nawawi al-Bantani dalam Tradisi Kajian Kitab Kuning (Kitab Klasik) di Pesantren Buntet," TAMADDUN, 4.Ed. 2 Juli-Desember (2016)

Maftuhin, Adhi, Sanad Ulama Nusantara, Transmisi Keilmuan Ulama Al-Azhar dan Pesantren disertai 
Hafidhuddin dan Saifuddin Zuhri Qudsy: Nawawi al-Bantani, Ashhab al-Jawiyyin di Bidang Hadis: Rihlah, Genealogi Intelektual, dan Tradisi Sanad Hadis

Biografi Penulis Kitab Kuning (Depok: Sahifa Publishing, 2018)

Mahdy, Fakhri Tajuddin, "Metodologi Syarah Hadis Nabi saw (Telaah Kitab Tanqih al-Qaul al-Hasis fi

Syarh Lubab al-Hadis karya Imam Nawawi al-Bantani)" (UIN Alauddin Makassar, 2016)

Mas'ud, Abdurrahman, Intelektual Pesantren Perhelatan Agama dan Tradisi (Yogyakarta: Lkis, 2004)

Mastuki HS, M. Ishom El-Saha, ed., Intelektual Pesantren, Potret Tokoh dan Cakrawala Pemikiran di Era Perkembangan Pesantren 2 (Jakarta: Diva Pustaka, 2004)

Minhaji, Akh., Sejarah Sosial dalam Studi Islam: Teori, Metodologi, dan Implementasi (Yogyakarta: Suka Press, 2013)

Muslih, Abdul Aziz, Sketsa Genealogi Kajian Hadis di Indonesia dari Masa Kerajaan hingga Pascakemerdekaan (Jawa Tengah: Sanjemedia Kebumen, 2016)

Muslimah, "Sejarah Masuknya Islam dan Pendidikan Islam Masa Kerajaan Banten Periode Pra Kemerdekaan," Jurnal Studi Agama dan Masyarakat, 13.No. 1 Juni (2017) <https://doi.org/10.23971/jsam.v13i1.576>

Nadhiran, Hedhri, "Kajian Kritis Kitab Maraqi al-'Ubudiyah (Analisis Metode Syarah Hadis Syekh Nawawi al-Bantani)," Jurnal Ilmu Agama, 21.No. 1 (2020)

Nurkholis, Mujiyo, Metode Syarah Hadis (Bandung: Fasygil Grup, 2005)

Putra, Apria, dan Chairullah Ahmad, Bibliografi Karya Ulama Minangkabau Awal Abad XX, Dinamika Intelektual Kaum Tua dan Kaum Muda (Padang: Komunitas Suluah-IHC, 2011)

Rohmana, Jajang A, “Authorship of The Jawi 'Ulama' in Egypt, A Contribution of Nawawi Banten and Haji Hasan Mustafa to Sharh Tradition," Epistemé: Jurnal Pengembangan Ilmu Keislaman, 15.No. 2 Desember (2020) <https://doi.org/10.21274/epis.2020.15.02.221-264>

Saifuddin Zuhri Qudsy, Ali Imran, Model-model Penelitian Hadis Kontemporer (Yogyakarta: Pustaka Pelajar, 2013)

Sakinah, Fatihatus, "Epistemologi Syarah Hadis Nusantara: Studi Syarah Hadith Tanqih al-Qaul alHasis fi Syarh Lubab al-Hadis karya Nawawi al-Bantani," Riwayah : Jurnal Studi Hadis, 6.No. 1 (2020) <https://doi.org/10.21043/riwayah.v6i1.6776>

Sejarah, LPSI-FK, Guru Orang-orang Pesantren (Pasuruan: Pustaka Sidogiri, 2013)

Siti Nur Kholilah, Kholilah Bidari, "Melacak Pemikiran Hadis Syeikh Nawawi al-Bantani," in Menelusuri Jejak Nabi saw, ed. oleh Komnas-Sunnah (Tangerang: alkitabah, 2013)

Steenbrink, Karel A., Beberapa Aspek tentang Islam di Indonesia Abad ke-19 (Jakarta: Bulan Bintang, 1984)

Suryadilaga, M. Alfatih, Metodologi Syarah Hadis (Yogyakarta: Suka Press, 2012)

Sya'ban, A. Ginanjar, Mahakarya Islam Nusantara, Kitab, Naskah, Manuskrip dan Korespondensi Ulama Nusantara (Ciputat: Pustaka Compass, 2017)

Ulum, Amirul, al-Jawi al-Makki, Kiprah Ulama Nusantara di Haramain (Yogyakarta: Global Press, 2010)

—, Nyai Khairiyah Hasyim Asy'ari Pendiri Madrasah Kuttabul Banat di Haramayn (Yogyakarta: Global Press, 2019)

—, Syaikh Nawawi al-Bantani, Penghulu Ulama di Negeri Hijaz (Yogyakarta: Global Press, 2019) Yatim, Badri, Sejarah Sosial Keagamaan Tanah Suci (Jakarta: Logos, 1999)

Zaini, Ahmad, "Pemikiran Tasawuf Imam Al-Ghazali," ESOTERIK, 2.1 (2017) <https://doi.org/10.21043/esoterik.v2i1.1902>

Zarif, Muhammad Mustaqim Mohd., "Penulisan Karya Hadis Nusantara Abad ke-19: antara Syeikh Nawawi Banten dan Syeikh Wan Ali Kutan al-Kalantani," in Sunnah Nabi Realiti dan Cabaran Semasa, ed. oleh Fauzi Deraman, Ishak Suliaman, dan Faizal Ahmad Shah (Kuala Lumpur: APIUM, 2011) 